\title{
Scientific and informational facilities for integrated risk management at Ural contaminated industrial site, Russia
}

\author{
N. M. Barysheva \\ FSUE RFNC-VNIITF named after Academician Zababakhin, Snezhinsk, \\ Chelyabinsk region, Russia
}

\begin{abstract}
This paper presents a model for the creation of a program for the remediation and development of contaminated industrial sites. The model was developed and implemented by taking the Ural town of Karabash, Russia, as an example. This paper (i) includes a detailed scientific analysis of the situation in the town, (ii) considers integrated risks to the health of the population and the regional environment connected to basic sources of danger and (iii) directs efforts to use internal recourses and innovative technologies for waste treatment and territory remediation. To provide the model implementation, a Computer Modeling System was developed.

Keywords: contaminated sites, remediation and development, integrated risks management, internal recourses, Computer Modeling System.
\end{abstract}

\section{Introduction}

This paper presents a model for the creation of a program for the remediation and development of contaminated industrial sites. The model was developed under the International Science and Technology Center projects Nos. 500 and 1872 and was implemented by taking the Ural town of Karabash, Russia, as an example.

The city of Karabash stands out against the grave environmental situation of the industrial Ural region. It is called 'a black spot of the planet'. In the early 20th century the city became a large center for mining and processing of the complex ores (containing copper, zinc, lead, silver, gold, etc.) of the Karabash deposit. A copper smeltery and later a concentrating mill were built there in 1910. In recent years, the city-forming industrial enterprise Karabash Copper- 
Smelting Combine (KMC) has released about 12 million tons of hazardous wastes, including mostly sulphurous anhydride (93\%), oxides of copper, zinc, lead, cadmium and arsenic (to 5\%) and others. The Joint Stock Company "KarabashMed", the successor to KMC, until recently used an outdated technology for blister copper production.

The city is located in the Soyman valley and is surrounded by mountains, far away from other sources of pollution. The climatic and geographic conditions of Karabash in some seasons (especially, winter) contribute to a higher concentration of hazardous substances in the ground-level atmosphere. Due to the processes of transport and spreading, the mineral (air, soil, snow and water from the well) and biological (agricultural products, living creatures) components of the Karabash ecosystem have accumulated an extreme complex of macro- and micro-elements posing a serious threat to public health.

The developed model (i) includes the detailed scientific analysis of the situation in the town; (ii) considers the risks to population health and regional environment connected to the basic sources of danger, (iii) directs efforts to use internal recourses and innovative technologies of waste treatment and territory remediation. To provide the model implementation, Computer Modeling System was developed. It provides informational on decision-making for managing integrated risks at contaminated industrial sites.

\section{Techniques and results}

The main stages of the work were as follows.

\subsection{Ecological priorities assessment}

This was the first stage of work. Based on studies of previous research and additional complex scientific research of the territory, the methodology of ecological priorities assessment has been developed and applied with the aim of risk minimization of contaminating sources on the health of the population and state of the environment:

To minimize the hazardous impact on public health, a four-level methodology was applied:

1. Comparison of the generalized parameters characterizing four sets of problems typical of the main industrial cities of the region and Karabash city, in particular: impact on the environment, current state of the environmental objects, public health and public concerns.

2. Comparison of the environmental parameters (about 40) of Karabash city with those of a "reference" city averaged over 4 reference cities, where the environmental conditions are the most favorable among the cities of the Chelyabinsk region.

3. Ecological and geochemical analysis of the processes of transport, spreading and accumulation of microelements in the individual objects of the city ecosystem. Determination of the statistically significant correlation and 
relationships between the contents of microelements in those objects and children's hair.

4. Multimedia risk assessment for Karabash based on the methodology currently considered to be the most reliable analytical tool for determining risk factors for the public health and their interplay, and for prioritizing the problems of environment contamination prevention based on the risk factors.

To achieve the objective, the following tasks were carried out:

- A large amount of information was acquired, analyzed and entered into the databases related to:

- $\quad$ the sources of contamination in the Karabash environment,

- the means of contamination spread in the environment,

- $\quad$ how potentially hazardous substances get into contact with human organisms;

- concentrations of the pollutants in the environment and biological objects, and

- medical and demographic parameters;

- A geo-information system (GIS) for Karabash city was created to present and analyze territory-specific data;

The official data on the state of the Karabash city environment and public health were obtained by the organizations authorized by the government to monitor and control the environment according to Russian standards and criteria. However, these data do not meet the requirements of the Project tasks as concerns the number of objects under study, the number of pollutants to be studied and in the completeness of the set of territory-specific parameters. The only exception is the data set on the town territory soil contamination with heavy metals obtained by Chelyabinsk Regional Center for Environmental Monitoring.

For this reason the system for monitoring the town ecosystem components was developed. Additional studies of territorial distributions of the concentration of hazardous agents in minerals (snow, soil, drinking water, lake bottom sediment) and biological components (edible roots, grass, milk, cows' hair and body parts, children's hair) of the city ecosystem were obtained. A register of town inhabitants taking into account gender and age structure, place of residence, drinking water supply and other factors was created. A corresponding database was developed for storing and processing the information.

Since there is no data on the monitoring of the atmospheric air, atmospheric transport of the pollutants has been simulated within the Project activities in three ways:

1. Direct simulation of the annual average concentrations using the transport code "Ecolog" certified in Russia and data from the inventory of the releasing sources at JSC "Karabash-Med".

2. Inverse simulation using U.S. code MEPAS allowing calculation of the concentration field based on the experimental data.

To show the whole range of the elements and substances released and discharged a set of snow samples taken within the town territory in winter 19992000 were studied and the following problems were solved: 
1. Determination of the total spectrum of contaminants in snow with the use of the up-to-date equipment,

2. Procurement of reliable data with the comparative analysis of the measurements done by several laboratories furnished with the metrologically certified equipment,

3. Study of the spreading patterns for the homogeneous mixture of contaminants within the Karabash territory under the landscape and weather conditions based on the contents of the contaminants at the different city points,

4. Analysis of the mechanisms of the territory contamination resulting from blister copper production,

5. Mineralogical and geochemical study of the snow to estimate the impact of waste releases on the environment and public health,

6. Reconstruction of the average concentrations of the contaminants in the atmosphere based on their contents in snow,

7. Since Karabash is situated near the contaminated territories of the Eastern Ural Radioactive Trace (EURT) and the industrial complex "Mayak" of the Ministry of Atomic Industry, the additional studies were carried out to reconstruct the average annual individual doses to the city population due to the radionuclide intake via inhalation of the radionuclide-containing snow

To visualize the area of distributed information, a GIS-application "Automatic workplace (AW) of Karabash investigator" which allows data mapping without code developer being created. The physical-chemical mechanisms of the town contamination were investigated. A model of microelement complex accumulation in objects of area ecosystem was developed. The following were determined:

- The accumulation of microelements in all examined objects of the Karabash ecosystem has a regular character and is caused by the dominated source of 'global' pollution for the whole Karabash area, namely copper-smelting production releases.

- The impact of the "global" source of pollution extends on microelements mass transfer in physico-chemical transmutation chains of contacted objects. All analyzed media form an interrelated system of the microelement transport, in particular:

- An obvious relationship between the contamination of soil and heavy metals contents in snow infiltrate is observed.

- The impact of soil composition near wells is almost negligible in those parts of the town where total soil contamination is minimal. Within the parts with a high level of total soil contamination, the soil layer is no longer a sorbing geochemical barrier.

- There is a peculiar barrier to the penetration of toxic elements in plants.

- The importance of microelement transport in watercontaining chains is determined. 
- The impact of forage microelements content on its contents in cattle tissues of heart, bone and hair inclined to accumulate hazardous substances is obviously observed. But we can't say the same about samples of biological liquids (urine, blood, cow milk).

Developed data base includes the following information about each inhabitant of the town: what air the people breathe, what water they drink, what soil they live on, what agricultural products grown in the city people consume and what harmful substances their bodies accumulate.

A thorough study of the territory and territory-specific concentrations of the pollutants allowed a multi-media assessment of carcinogenic risk and risk of excessive deaths due to airborne particles and sulphur dioxide released by JSC "Karabashmed". The table below shows the ways of intake and the substances taken into account in the assessment of carcinogenic risk as marked with crosses.

Table 1.

\begin{tabular}{|l|c|c|c|c|}
\hline & Inhalation intake & \multicolumn{3}{|c|}{ Ingestion intake } \\
\hline Ingredients & Air & Soil & Water & Potatoes \\
\hline Cadmium & + & + & + & + \\
\hline Arsenic & + & + & + & + \\
\hline Nickel & + & & & \\
\hline Lead & + & + & + & + \\
\hline Chloroform & & & + & \\
\hline
\end{tabular}

Risk assessment shows:

- the largest carcinogenic risk to the public health is caused by the ingestion intake of drinking water and potatoes,

- $\quad$ arsenic and cadmium entering the organisms via all considered paths pose the greatest carcinogenic threats;

- the largest annual population risk of excessive deaths is caused by:

- airborne particles,

○ sulphur dioxide,

o total carcinogenic risk,

The project implementation results in the following practical conclusions regarding the need to:

1. Change the modes of gas and dust purification at specific stages of copper smelting technology,

2. Introduce some certain changes into the system of drinking water supply of the city,

3. Decrease the consumption of products grown within the city territory;

To assess the influence of the Karabash industrial zone on the regional environment:

1. The impact of accumulated industrial wastes on the region water system was assessed: 
- Mechanism of metallurgical slag stability in changing physical and chemical conditions of the environment was studied with use of two main tests: 1) the test of the characteristic of toxicity of waste products, 2) the generalized leaching test waste products.

- The sulphide-bearing waste product drainage zones with acid mine waters was studied. The surface of fine dispersive dust occupies a large area and is subjected to erosion. This was also studied.

- Sleems from the neutralization of acid mine waters are technogenic sediments under study. They were formed as a result of a mix of acid mine waters with neutral waters from the Olkhovka River.

Wastes were mapped and codes to calculate the reserves of useful components were created.

2. Monitoring of the main transport media of hazardous substances from the Karabash industrial zone was performed. Surface waters, drawn suspension and bottom sediments of surface flows were considered. The influence of the Karabash industrial zone on Argazy water storage which is the source of drinking water for the city of Chelyabinsk was assessed.

3. Debits of surface and concealed waters as one of the main characteristics of metals transport to Sak-Elga River were determined by the method of "chemical charge" (X-charge). Lithium ( $\mathrm{Li}$ ) in the form of lithium chloride solution was used as a chemical tag. In parallel, concealed inflows were determined and their contribution to the heavy-metal loading of the surface water flows were assessed.

4. The rate of the technogenic pollution accumulation in the bottom sediments of the lakes was estimated with the method of direct gamma-spectrometry of the bottom sediment samples to detect Cs137.

The work carried out allowed the creation of a model of a Karabash water system to calculate the water balance and surface water quality.

\subsection{Resource priorities assessment}

This was the second stage of work. Internal resources of the town are technogenic. They contain considerable amount of valuable components: copper, zinc, gold, silver, platinoids, rare earth elements, and rare and scattered metals. Physical and chemical features and transformations in original technogenic wastes and in different technological processes were investigated to assess the possibility of effective reprocessing and the potential impact upon environment during the reprocessing.

The comparative analysis of all the data collected under the project showed that physical and chemical processes producing different types of wastes have profound common similarities. The method developed under the project allowed us with known accuracy to restore contents of phases (wastes) by incomplete data of chemical analysis and to supplement the overall picture of chemical composition. 


\subsection{Technological priorities assessment}

This was the third stage. The three units of interconnected technologies were considered: waste reprocessing, territory remediation and population remediation. To assess technological priorities the following were done:

- A database of technologies was created. The data base structure was oriented for the primary assessment of technologies within the frames of the project. The list of formalized assessments with use of the List, the structure of which is typical for many environmental agencies in the EU and the USA, including the risk of technological implementation was developed for characteristic of technological proposals. Available technologies were given according to this form.

- Information on active and passive technologies of handling of acid drainage waters and sulfide-containing wastes collected from different sources was also included on the database. The structure of both parts is identical.

- Technology assessment criteria were chosen. The algorithm for expert assessment of technologies based on Cohren's Q-test that was proposed by the project authors was proposed and realized. Technologies were analyzed from the point of view of the chosen criteria.

As a result of this work, a selection of consistent technologies for waste handling and the remediation of an area and its people were made, as well as the formulation, on this basis, of a 'Remediation and Development Program'.

\section{Conclusions}

The implementation of the proposed model for creating a program for the remediation and development of contaminated industrial sites in Karabash is a unique experience of (i) preliminary work for integrated risk management at an Ural contaminated industrial site, and (ii) the development of corresponding information technologies to provide a wide scale of technical and policy decision-making. A scientific and informational basis for moving towards stable development, the improvement of the environmental and economic situation in the town is created.

The model and Computer Modeling System developed, which took the town of Karabash as an example, can be used at other contaminated industrial sites in Russia and other countries.

\section{References}

[1] N.M. Barysheva, E.V. Polyakov, V.N. Udachin, A.G. Uralshin, E.O. Shrumm. "Karabash: the zone of special concern". Materials of the CPEXIII conference "Chemistry for environment protection", June 9- 13, 2002, Hilo, USA.

[2] N.M. Barysheva, N.V. Garmasheva, E.V. Polyakov, V.T. Surikov, V.N. Udachin. "Comparative multi-elemental analysis of mineral and biological 
components of the ecosystem "Karabash-city", co-existing with blister copper production plant. Physico-chemical point of view". Materials of the CPEXIII conference "Chemistry for environment protection", June 913, 2002, Hilo, USA.

[3] N.M. Barysheva, E.V. Polyakov, N.V. Garmasheva, V.T. Surikov, V.N. Udachin. "Physical-chemical point of view on the chemical composition of mineral and biological components of the ecosystem Karabash-city". Materials of the STCU Workshop "Ecological and Health Threat Associated with Environmental Contamination'02”, October 14-18, 2002, Kiev, Ukraine.

[4] N.M. Barysheva, A.G. "Ural'shin. "Reconnoitring Assessment of Risk to Public Health in Karabash". Materials of the IX Congress dedicated to the $80^{\text {th }}$ anniversary of the State Center for Sanitary and Epidemiological Inspection of the Russian Federation, November 2002, Chelyabinsk.

[5] N.M. Barysheva, E.N. Avrorin and others. "Experience in Working out a Program of Remediation and Development of Ural Old-Time Industrial Region". Materials of the 17th World Conference on Ecological Restoration, September 11- 19, 2005, Saragoza, Spain.

[6] N.M. Barysheva, E.V. Polyakov, V.N. Udachin, G.P. Shveikin. "Remediation of Soil and Water in Minerals Mining and Working Areas of Ural, Russia, Taking the Town of Karabash for Example". Materials of the "9th International FZK//TNO Conference on Soil/Water-Systems", October 1-7, 2005, Bordeaux, France. 